\title{
Frequiência de anticorpos contra Borrelia burgdorferi em cães na região metropolitana do Rio de Janeiro ${ }^{1}$
}

\author{
Alessandra de Lacerda Alves $^{2}$, Renata Cunha Madureira ${ }^{3}$, Rosângela Antunes da \\ Silva $^{4}$, Fabíola do Nascimento Corrêa ${ }^{5 *}$ e Rita C.C. Machado Botteon ${ }^{5}$
}

\begin{abstract}
Alves A.L., Madureira R.C., Silva R.A., Corrêa F.N. \& Botteon R.C.C.M. 2004. [Frequency of antibodies against Borrelia burgdorferi in dogs from the metropolitan region of Rio de Janeiro.] Frequiência de anticorpos contra Borrelia burgdorferi em cães na região metropolitana do Rio de Janeiro. Pesquisa Veterinária Brasileira 24 (4):203-206. Depto Medicina e Cirurgia Veterinária, Inst. Veterinária, UFRRJ, Seropédica, RJ 23851-970, Brazil. E-mail: fabiolanc@ig.com.br

Lyme disease is a worldwide zoonosis caused by Borrelia burgdorferi (Spirochaetae) and transmitted through ticks (Ixodidae). Many species of domestic and wild animals are affected. The dog is an important reservoir in the domiciliary environment. The disease affects the joints and causes alterations in other organs. Blood serum samples from $143 \mathrm{dogs}$, living in the counties of Seropédica, Itaguaí and Rio de Janeiro, were analyzed with the indirect ELISA test, to search for antibodies against Borrelia burgdorferi latu sensu. Average positive results were $48.25 \%, 41.9 \%$ in Seropédica, 4.9\% in Itaguaí and 1.4\% in Rio de Janeiro. The titres varied from 1:400 to 1:6400. The prevalence was lower $(p<0.05)$ in dogs up to one year of age than in older dogs, with significant difference. Between males and females was no statistical difference with positives titres. The result of this survey should draw attention to the occurrence of Borrelia sp in the area studied, considering the importance of Lyme disease as an emerging zoonosis.
\end{abstract}

INDEX TERMS: Borrelia burgdorferi, Spirochaetae, dogs, enzyme immunoassay, serology.

RESUMO.- Borreliose de Lyme é uma zoonose cosmopolita causada pelo espiroquetídeo Borrelia burgdorferi e tem como vetores carrapatos ixodídeos. Esta espiroqueta acomete diversas espécies de animais domésticos e silvestres, sendo o cão um importante reservatório no ambiente domiciliar. O quadro clínico da doença envolve as articulações, além de causar alterações em vários sistemas do organismo. Foram analisados 143 soros de cães provenientes dos municípios de Seropédica, Itaguaí e do

\footnotetext{
${ }^{1}$ Recebido em 28 de maio de 2004.

Aceito para publicação em 8 de julho de 2004.

2 Discente do Curso de Medicina Veterinária da Universidade Federal Rural do Rio de Janeiro (UFRRJ). Bolsista de Iniciação Científica PIBIC/

${ }^{3}$ Discente de Doutorado em Ciências Veterinárias da UFRRJ. E-mail: renatacm@ufrrj.br

${ }^{4}$ Discente do Curso de Medicina Veterinária da UFRRJ. Bolsista de Iniciação Científica da FAPERJ. E-mail: rhoas@ig.com.br

${ }^{5}$ Discente do Curso de Medicina Veterinária da UFRRJ. Bolsista de Iniciação Científica PIBIC/CNPq. *Autor para correspondência. E-mail: fabiolanc@ig.com.br

${ }^{6}$ Departamento de Medicina e Cirurgia Veterinária, Inst. Veterinária, UFRRJ, 23851-970 Seropédica, RJ.
} CNPq.
Rio de Janeiro, Estado do Rio de Janeiro, quanto à ocorrência de anticorpos contra $B$. burgdorferi latu sensu, através de teste de ELISA indireto. Foram encontrados $48,25 \%$ de animais soropositivos, sendo 41,9\% em Seropédica, 4,9\% em Itaguaí e 1,4\% no Rio de Janeiro. Os títulos variaram de 1:400 a 1:6400. Cães com menos de um ano apresentaram menor índice de títulos positivos, sendo a diferença significativa. Entre machos e fêmeas, não houve diferença significativa entre os títulos positivos. O resultado encontrado deve servir como alerta para ocorrência de Borrelia sp nas regiões estudadas, considerando a importância da borreliose de Lyme como zoonose emergente.

TERMOS DE INDEXAÇÃO: Borrelia burgdorferi, Spirochaetae, cães, ensaio imunoenzimático, sorologia.

\section{INTRODUÇÃO}

Borreliose de Lyme é uma zoonose cosmopolita causada pelo espiroquetídeo Borrelia burgdorferi e tem como vetores carrapatos ixodídeos. No Brasil, essa enfermidade foi descrita em seres humanos (Azulay et al. 1991, Yoshinari et al.1993a,b, Yoshinari et al. 1997), sendo denominada de borreliose de Lyme-like por Yoshinari et al. (2000). Em animais, estudos sorológicos foram realizados em bovinos (Ishikawa 1996, 2000), cães (Soares et al. 
1999, Joppert et al. 2001), e eqüinos (Salles et al. 2002, Madureira 2004) onde foram observadas reações positivas para esse agente.

O primeiro relato de borreliose em cães foi descrito em área endêmica para doença de Lyme nos EUA, onde esses animais apresentavam-se com febre e dor nos quatro membros. Os cães são importantes reservatórios de borrélia, podendo ser isoladas espiroquetas de animais clinicamente sadios (Burgess 1986, Merino et al. 2000). Carrapatos do gênero Ixodes são os principais vetores do espiroquetideo (Soares et al. 2000), porém a transmissão desse agente também pode ocorrer por Dermacentor variabilis ou Amblyomma americanum (Mather et al. 1994).

Segundo Coyle (1993), no homem ocorre uma condição inflamatória multissêmica não contagiosa, sendo o sítio da picada do carrapato infectado porta de entrada para o agente etiológico. Os primeiros sintomas podem aparecer dias ou semanas após a exposição do agente e consistem num eritema migratório, linfadenite localizada, glomerulonefrite por deposição de imunocomplexo, mal estar, fadiga, cefaléia, rigidez na nuca, dores musculares e articulares, podendo evoluir para artrites e patologias nervosas e circulatórias mais graves, se a doença não for diagnosticada logo no início.

A doença em animais domésticos manifesta-se por síndrome músculo-esquelética, invariável quanto à idade, raça ou sexo, caracterizada por comprometimento de diversas articulações e quadro de artrite progressiva (Lissman et al. 1984, Levy \& Dreesen 1992, Straubinger et al. 1998, Straubinger 2000). Pode acorrer eritema no local da picada do carrapato (Appel 1990), além de febre, letargia, anorexia e emagrecimento progressivo (Magnarelli et al. 1995). Outros sintomas como meningite, uveíte, glomerulonefrite e cardiopatias têm sido relatadas (Parker \& White 1992, Duray 1993, Mackenna et al.1995,).

O diagnóstico da borreliose de Lyme pode ser conclusivo levando em consideração vários fatores, destacando-se a sintomatologia clínica, epidemiologia e sorologia positiva (Steere 1989). O ensaio de imunoadsorção enzimática (ELISA) indireto tem sido o método de diagnóstico mais empregado e reconhecido para identificar anticorpos anti-Borrelia sp com segurança (Gordillo et al. 1999). O conhecimento da soroprevalência de $B$. burgdorferi latu sensu em cães pode constituir-se em importante indicador da dispersão do agente etiológico (Hoskins 1991) em nosso meio.

O objetivo deste trabalho foi verificar a frequiência de anticorpos anti-B. burgdorferi em cães sem sintomas clínicos de borreliose, procedentes da região do “Grande Rio de Janeiro”, RJ.

\section{MATERIAL E MÉTODOS}

Nos anos de 2000 a 2002 foram obtidas 143 amostras de soro de cães, machos e fêmeas de diferentes idades, domiciliados nos municípios de Seropédica (117) e Itaguaí (20), Estado do Rio de Janeiro, e Bonsucesso, Bairro do Município do Rio de Janeiro (6). As amostras avaliadas consistiram de uma amostragem não probabilística, sendo alguns animais sem evidência clínica de enfermidades, outros altamente parasitados por pulgas e/ou carrapatos e enfermos (sintomas de outras doenças). As amostras foram obtidas por punção da veia radial ou safena em seringas de $5 \mathrm{ml}$ e posteriormente transferidas para frascos sem anticoagulante.
O sangue foi centrifugado e os soros obtidos foram acondicionados em frascos tipo Eppendorf e mantidos a $-20^{\circ} \mathrm{C}$ até o momento da análise sorológica.

As amostras de soros coletadas foram analisadas através do ELISA indireto para detecção de anticorpos homólogos da classe $\lg G$ contra B. burgdorferi latu sensu, conforme técnica padronizada por Soares et al. (1999), no laboratório de Doenças Parasitárias do Convênio "Projeto Sanidade Animal Embrapa/UFRRJ".

Foram utilizados oito soros controles negativos de animais provenientes de um canil particular e um soro controle positivo de animal inoculado experimentalmente. A linha de corte (cut-off) foi estabelecida com um grau de confiança de $99,99 \%$, segundo a média mais três vezes o desvio padrão dos valores da densidade óptica dos controles negativos.

\section{RESULTADOS E DISCUSSÃO}

A análise soro-epidemiológica das 143 amostras de soros revelou que 69 animais foram reagentes positivos $(48,25 \%)$ ao ELISA indireto com titulações entre 1:400 e 1:6400 (Quadro 1). Foram encontrados $41,9 \%(60 / 143)$ de animais positivos provenientes de Seropédica, 4,9\% (7/143) de Itaguaí e 1,4\% (2/143) de Bonsucesso.

Em relação ao total de amostras obtidas em cada município, observou-se que em Seropédica ocorreram proporcionalmente mais animais positivos $(51,28 \%)$. Esse fato pode ser justificado em parte pelo tipo de criação com acesso freqüiente à rua, contato com animais errantes e possibilidade de maiores e mais freqüientes infestações por carrapatos. Constatou-se ainda que a maioria dos cães procedentes de Seropédica tem contato com animais de outras espécies, sobretudo eqüinos e bovinos cria-

Quadro 1. Freqüência sorológica de anticorpos antiBorrelia burgdorferi em cães $(n=143)$ domiciliados nos municípios de Seropédica, Itaguaí e Rio de Janeiro (Bairro de Bonsucesso), determinado pelo ELISA indireto, entre os anos de 2000-2002

\begin{tabular}{ccccc}
\hline \multirow{2}{*}{ Título } & Prevalência & \multicolumn{2}{c}{ Positivos (n) } & \multirow{2}{*}{ Negativos } \\
\cline { 3 - 4 } & & Relativa & Absoluta & \\
\hline $1: 400$ & 44 & $63,77 \%$ & $30,77 \%$ & - \\
$1: 800$ & 17 & $24,63 \%$ & $11,88 \%$ & - \\
$1: 1600$ & 4 & $5,80 \%$ & $2,80 \%$ & - \\
$1: 3200$ & 2 & $2,90 \%$ & $1,40 \%$ & - \\
$1: 6400$ & 2 & $2,90 \%$ & $1,40 \%$ & - \\
Total positivos & 69 & $100,00 \%$ & $48,25 \%$ & - \\
Total negativos & - & $(69 / 69)$ & $69 / 143)$ & \\
& & - & $51,75 \%$ & 74
\end{tabular}

Quadro 2. Freqüência sorológica de anticorpos antiBorrelia burgdorferi em cães $(n=143)$ domiciliados nos municípios de Seropédica, Itaguaí e Rio de Janeiro (Bairro de Bonsucesso), determinado pelo ELISA indireto, entre 2000 e 2002, em relação à observação de parasitismo por carrapato no momento da coleta de sangue

\begin{tabular}{ccccc}
\hline & Parasitados & Não Parasitados & Não observado & Total \\
\hline Positivos & $20,28 \%(29)$ & $23,08 \%(33)$ & $4,90 \%(7)$ & $48,25 \%(69)$ \\
Negativos & $25,87 \%(37)$ & $20,28 \%(29)$ & $5,59 \%(8)$ & $51,75 \%(74)$ \\
Total & $46,15 \%(66)$ & $43,36 \%(62)$ & $10,49 \%(15)$ & $100 \%(143)$
\end{tabular}


Quadro 3. Freqüência sorológica de anticorpos antiBorrelia burgdorferi quanto ao sexo em cães $(n=143)$, domiciliados nos municípios de Seropédica, Itaguaí e Rio de Janeiro (Bairro de Bonsucesso), determinado pelo ELISA indireto, entre os anos de 2000 a 2002

\begin{tabular}{cccc}
\hline & Fêmeas & Machos & Total \\
\hline \multirow{2}{*}{ Positivos } & $27,85 \%$ & $20,71 \%$ & $49,28 \%$ \\
& $(39)$ & $(29)$ & $(69)$ \\
Negativos & $25 \%$ & $26,42 \%$ & $52,85 \%$ \\
& $(35)$ & $(37)$ & $(74)$ \\
Total & $52,85 \%$ & $47,14 \%$ & $100 \%$ \\
& $(74)$ & $(66)$ & $(140)$
\end{tabular}

mente a diferença entre machos e fêmeas não foi significativa. Três animais não entraram nesta análise porque o preenchimento de suas fichas estava incompleto, não contendo essa informação.

Quanto à idade (Quadro 4), entre os cães mais jovens a frequiência de positivos foi baixa e obteve-se os menores títulos. Cerca de 9\% dos cães com menos de um ano apresentaram títulos de 1:400. Por outro lado, títulos mais elevados foram registrados em cães com cinco anos ou mais, em semelhança com os dados obtidos por Greene et al. (1988b), utilizando Imunofluorescência Indireta (IFI). Magnarelli et al. (1985) encontraram maior número de casos positivos, na IFI, em cães

Quadro 4. Freqüência sorológica de anticorpos anti-Borrelia burgdorferi por faixa etária em cães $(n=143)$, domiciliados nos municípios de Seropédica, Itaguaí e Rio de Janeiro (Bairro de Bonsucesso), determinado pelo ELISA indireto, entre os anos de 2000 e 2002

\begin{tabular}{ccccccc}
\hline & $<1$ ano & $=1$ ano $<3$ anos & $=3$ anos $<5$ anos & $=5$ anos & Não informado & Total \\
\hline \multirow{2}{*}{ Positivos } & $1,40 \%$ & $9,79 \%$ & $9,09 \%$ & $12,58 \%$ & $15,39 \%$ & $48,25 \%$ \\
& $(2)$ & $(14)$ & $(13)$ & $(18)$ & $(22)$ & $(69)$ \\
Negativos & $13,99 \%$ & $13,99 \%$ & $7,69 \%$ & $6,29 \%$ & $9,79 \%$ & $51,75 \%$ \\
& $(20)$ & $(20)$ & $(11)$ & $(9)$ & $(14)$ & $(74)$ \\
Total & $15,39 \%$ & $23,78 \%$ & $16,78 \%$ & $18,87 \%$ & $25,18 \%$ & $100 \%$ \\
& $(22)$ & $(34)$ & $(24)$ & $(27)$ & $(36)$ & $(143)$
\end{tabular}

dos em terrenos baldios e animais silvestres. Torrence et al. (1990), ao relacionar a prevalência de borreliose canina com o grau de exposição destes animais aos vetores, sugere que cães com acesso à rua estão mais expostos à população de carrapatos pela falta de controle parasitário e têm maiores chances de desenvolver a enfermidade. No presente estudo todos os cães provenientes de Seropédica tinham acesso à rua, diferentemente daqueles provenientes de Bonsucesso e Itaguaí e os títulos confirmam a possibilidade de maior exposição ao agente, contudo sem diferença significativa (Quadro 2).

A frequiência de anticorpos $(48,25 \%)$ encontrada no presente estudo foi superior à observada por Soares et al. (1999), que ao analisarem soros de cães da Baixada Fluminense por meio do ensaio ELISA indireto, encontraram 20\% (30/150) dos animais positivos. Joppert et al. (2001), utilizando a mesma técnica, observaram 9,7\% (23/237) dos cães provenientes de Cotia, SP reagentes ao ensaio. Ambos os trabalhos não observaram reações cruzadas significativas entre anticorpos de B. burgdorferi e variantes sorológicas de Leptospira $\mathrm{sp}$. Os dados foram igualmente superiores aos relatados por Torrence et al. (1990) em Virgínia nos EUA; Ulmer et al. (1999) na França, Greene et al. (1988a), na Carolina do Norte, EUA, e Rojo Vazquez (1997) em Leon na Espanha.

O resultado observado no presente estudo corrobora com os encontrados em áreas endêmicas para borreliose de Lyme nos EUA, onde foram relatados sorologias para cães, variando de 40 a $89 \%$ de animais soropositivos (Burgess 1986, Cohen et al. 1990, Magnarelli et al. 1985, 1987, 1990, Levy \& Magnarelli 1992), assim como por Azuma et al. (1994) que encontraram $76,2 \%$ de cães positivos em Hokkaido, Japão.

Em relação ao sexo, observou-se a maior freqüência de títulos positivos entre as fêmeas (Quadro 3), contudo estatistica- com mais de quatro anos. Análise estatística da variável idade revelou diferença significativa $(p<0,05)$ entre cães com menos de um ano em relação às outras faixas etárias. Em parte, isto se deve provavelmente ao fato de os animais jovens estarem há menos tempo expostos ao agente, devido a baixos níveis de anticorpos colostrais ou por não haverem desenvolvido a imunidade ativa com níveis de anticorpos suficientes para serem detectados no teste ELISA (Merino et al. 2000). No entanto, Joppert et al. (2001) não observaram diferença significativa em relação à faixa etária em cães no Estado de São Paulo.

\section{CONCLUSÕES}

O grande número de animais positivos deve servir como alerta para ocorrência de Borrelia sp nas regiões estudadas, sugerindo atenção aos Médicos Veterinários e agentes de saúde pública, considerando a importância da borreliose de Lyme como zoonose emergente.

\section{REFERÊNCIAS}

Appel M.J.G., Allan S., Jacobson R.H., Lauderdale T.L., Chang Y. F., Shin S.J., Thomford, J. W., Todhunter R.J. \& Summers B.A. 1993. Experimental Lyme disease in dogs produces arthrits and persistent infection. J. Infect. Dis. 167:651-664.

Azulay R.D., Abulafia L.A., Sodré C.T., Azulay D.R. \& Azulay M. M. 1991. Lyme disease in Rio de Janeiro, Brazil. Int. J. Dermatol. 30:569-571.

Azuma Y.J., R.H., Lauderdale T.L., Chang Y.F., Shin S.J., Thomford, J. W., Todhunter R. J. \& Summers B.A. 1994. Canine disease: clincal and serological evoluations in 21 dogs in Japan. Vet. Rec.134:369-372.

Burgess E.C. 1986. Natural exposure of Wisconsin dogs to the Lyme disease spiroquete Borrelia burgdorferi. Laboratory Anim. Sci. 36(3):288-290.

Coyle P.K. 1993. Lyme Disease. Mosby Year Book, St. Louis, Missouri. $235 p$. 
Cohen N.D. \& Cohen D. 1990. Borreliosis in horses: a comparative review. Compendium 12(10):1449-1458.

Duray P.H. 1993. Histopathology of Human Borreliosis, p.49-58. In: Coyle P.K. (ed.) Lyme Disease. Mosby Year Book, St. Louis.

Gordillo G., Torres J., Solorzano F., Cedillo-Rivera R., Taipa-Conyer \& Muñoz O. 1999. Serologic evidences suggesting the presence of Borrelia burgdorferi infection in Mexico. Archs Med. Res. 30:64-68.

Greene R.T., Levine J.F., Breitschwerdt E. B. \& Berkhoff H.A. 1988a. Antibodies to Borrelia burgdorferi in dogs in North Carolina. Am. J. Vet. Res. 49(4):473-476.

Greene R.T., Walker R.L.., Nicholson W.L.., Heidner H.W., Levine J.F., Burgess E.C., Wyand M., Breitschwerdt E.B. \& Berkhoff H.A. 1988b. Immunoblot analysis of immunoglobulin $\mathrm{G}$ response to the Lyme disease agent (Borrelia burgdorferi) in experimental and naturally exposed dogs. J. Clinical Microbiol. 26(4):648-653.

Hoskins J.D. 1991. Tick-borne zoonoses: Lyme disease, Ehrlichiosis and Rocky Mountain spotted fever. Small Animal 6:236-243.

Ishikawa M. M. 1996. Epidemiologia da borreliose de Lyme em bovinos na Região Sudeste do Brasil e padronização do diagnóstico sorológico. Dissertação (Mestrado em Parasitologia Veterinária), Curso de Pós-graduação em Ciências Veterinárias, Universidade Federal Rural do Rio de Janeiro, Seropédica, RJ. 51p.

Ishikawa M.M. 2000. Perfil da produção de anticorpos anti-Borrelia burgdorferi em bovinos e estudo de infecções simultâneas com diferentes estímulos antigênicos, em condições experimental e natural. Tese (Doutorado em Parasitologia Veterinária), Curso de Pós-graduação em Ciências Veterinárias, Universidade Federal Rural do Rio de Janeiro, Seropédica, RJ. 80p.

Joppert A.M., Hagiwara M.K. \& Yoshinari N.H. 2001. Antibodies in dogs from Cotia county, São Paulo State, Brazil. Revta Inst. Med. Tropical, São Paulo, 43(5):251-255.

Levy S. A.. \& Dreesen D.W. 1992. Lyme borreliosis in dogs. Canine Practice 17:5-14.

Levy S.A. \& Magnarelli L.A. 1992. Relationship between development of antibodies to Borrelia burgdorferi in dogs and the subsequent development of limb/joint borreliosis. J. Am. Vet. Med. Assoc. 200(3):344-347.

Levy S.A.. \& Magnarelli L.A. 1992. Relationship between development of antibodies to Borrelia burgdorferi in dogs and the subsequent evelopment of limb/joint borreliosis. J. Am. Vet. Med. Assoc. 200(3):344-347.

Lissman,B.A., Jacobson R.H., Lauderdale T.L., Chang Y.F., Shin S.J., Thomford J. W., Todhunter R.J. \& Summers B.A. 1984. Spirochete-associated arthritis (Lyme Disease) in a dog. J. Am. Vet. Med. Assoc.185(2):219-220.

Madureira R.C. 2004. Freqüência de anticorpos homólogos anti-Borrelia burgdorferi em eqüinos dos municípios de Três Rios, Vassouras e Valença, estado do Rio de Janeiro. Dissertação (Mestrado em Parasitologia Veterinária), Curso de Pós-graduação em Ciências Veterinárias, Universidade Federal Rural do Rio de Janeiro, Seropédica, RJ. 46p.

Magnarelli L.A., Jacobson R.H., Lauderdale T.L., Chang Y.F., Shin S.J., Thomford J.W., Todhunter R.J. \& Summers B.A. 1985. Borreliosis in dogs from southern Connecticut. J. Am. Vet. Med. Assoc. 189:955-959.

Magnarelli L.A., Anderson J.F., Schreier A.B. \& Ficke C.M. 1987. Clinical and serologic studies of canine borreliosis. J. Am.Vet.Med. Assoc. 191:1089-1094.

Magnarelli L.A., Anderson, J.F. \& Schreier A.B. 1990. Persistence of antibodies to Borrelia burgdorferi in dogs of New York and Connecticut. J. Am. Vet. Med. Assoc. 196(7):1064-1068.

Magnarelli L.A., Anderson J.F. \& Johnson R.C. 1995. Analyses of mammalian sera in enzyme-linked immunosorbent assays with different strain of Borrelia burgdorferi sensu lato. J. Wild Dis. 31(2):159-165.

Mather T.N., Fish D. \& Coughlin R.T. 1994. Competence of dogs as reservoirs for Lyme disease spirochetes (Borrelia burdorferi). J. Am. Vet. Med. Assoc. 205(2):186-188.

Mckenna P. 1995. Canine Lyme disease in Belgium. Vet. Rec. 136:224-247.

Merino F.J., Serrano J.L., Saz J.V., Nebreda T., Gegundez, M. \& Beltran M. 2000. Epidemiological characteristics of dogs with Lyme borrelioses in the province of Soria. European J. Epidemiol. 16(2):97-100.

Parker J.L. \& White K.W. 1992. Lyme borreliosis in cattle and horses: a review of the literature. Cornell Vet. 82:253-274.

Rojo V.J. 1997.Soroprevalencia de la infección por Borrelia burgdorferi y Rickettsia en población humana y canina de la Zona Básica de Salud de San Andrés del Rabanedo (Leon, España). Revta Española Salud Publica 71(2):173-180.

Salles R.S., Fonseca A.H., Scofield A., Madureira R.C. \& Yoshinari N.H. 2002. Sorologia para Borrelia burgdorferi latu sensu em eqüinos no estado do Rio de Janeiro. Hora Vet., Porto Alegre, 127:46-49.

Soares C.O., Fonseca A.H., Ishikawa M.M., Manera G.B., Scofield A. \& Yoshinari N.H. 1999a. Sorologia para borreliose em cães procedentes da Baixada Fluminense, Estado do Rio de Janeiro. Revta Bras. Med. Vet. 21(3):111-114.

Soares C.O., Scofield A., Manera G.B., Ishikawa M.M., Fonseca A.H. \& Yoshinari N.H. 1999b. Ensaio imunoenzimático indireto para detecção de anticorpos homólogos da classe IgG contra Borrelia burgdorferi latu sensu em cães. Revta Bras. Med. Vet. 21(4): 153-158.

Soares C.O., Ishikawa M.M., Fonseca A.H. \& Yoshinari N.H. 2000. Borrelioses, agentes e vetores. Pesq. Vet. Bras. 20(1):1-19,

Steere, A. C. 1989. Lyme disease. Engl. J. Medicine 31:586-597.

Straubinger R.K., Straubinger A.F., Summers B.A., Jacobson R.H. \& Erb H.N. 1998. Clinical manifestations, pathogenesis and effect of antibiotic treatmet of Lyme borreliosis in dogs. Wiener Klinische Wchschr. 110:874-81.

Straubinger R.K. 2000. PCR-Based quantification of Borrelia burgdorferi organismis in canine tissues over a 500-day postinfection period. J. Clinical Microbiol. 38:2191-2199.

Torrence M. E., Suzanne R.J., Jay F.L., William L.N. \& Kevin D.P. 1990. Serosurvey of shelter dogs in Virginia for antibodies to Borrelia burgdorferi. Preventive Vet. Med. 10(1-2):41-46.

Ulmer P., Fertè H., Mercier A. \& Richard S. 1999. Borreliose de Lyme: enquête épidémiologique réalisée dans um chenil du nord-est de la France. Revue Française Laboratoriale 310:49-56.

Yoshinari N.H., Oyafuso L.K., Monteiro F.G.V., Barros P.J.L., Cruz F.C.M., Ferreira, L. G. E., Bonasser F., Baggio D. \& Cossermelli W. 1993a. Doença de Lyme: Relato de um caso observado no Brasil. Revta Hospital das Clinicas Fac. Med. São Paulo 48(4):170-174.

Yoshinari N.H., Steere A.C., Barros P.J.L., Cruz F.M.C., Mendonça M., Oyafuso L.K., Levy L.\& Cossermelli W. 1993b. Lyme disease in Brasil: report of five cases. Revta Española Reumatol. 20:6.

Yoshinari N.H., Barros P.J.L., Bonoldi V.L.N., Ishikawa M., Battesti D.M.B., Pirana S., Fonseca A.H. \& Schumaker T.T. 1997. Perfil da Borreliose de Lyme no Brasil. Revta Hospital das Clínicas Fac. Med. São Paulo 52(2):111117.

Yoshinari N.H., Soares C.O., Fonseca A.H., Scofield A., Battesti D.B. \& Madruga C.R. 2000. Serology for Babesia bovis in human patients with Lyme-like disease syndrome, syphilis, septicemia and autoimmune diseases. Annals XXI Int. Congr. Entomology, vol. 2, no.1, p.820-820. 